\title{
Ergonomic Evaluation of the Rural Women While Performing Wheat Harvesting Activity
}

\author{
Jyotsna, K. Rana, K. Singh* and M. Mehta \\ Department of Family Resource Management, CCS Haryana Agricultural University, \\ Hisar, Haryana, India
}

KEYWORDS Posture. Wheat Harvesting. Physiological Cost of Work. Heart Rate

\begin{abstract}
The study was undertaken in Ludas village of Hisar district of Haryana State to determine the Physical fitness, time and activity profile, physiological and biomechanical stress of women while performing the wheat harvesting activity. The field experiment was carried out on 20 women each falling between the two age group viz. $25-35$ and $35-45$ years. The results revealed that mean age of the respondents was 32.1 years, mean body height was $158.6 \mathrm{~cm}$ and mean weight was $47.7 \mathrm{~kg}$. Majority of respondents from both the age group fall under the category of ectomorphs (75\%). On the physical fitness index (PFI), maximum number of respondents falls under the category of high average (60\%). On an average, women spent 8 hours in wheat harvesting activity and 2 hours in bundling activity per day. They cover an average distance of $2.2 \mathrm{~km}$ and tie an average of 50 bundles per day. They spent 25 man-days in wheat harvesting and 5 man-days in bundling activity per year. Average heart rate of women was found to be 121.5 beats/min. which increased up to 126.7 beats $/ \mathrm{min}$ at the end of the activity during evening. Similarly, energy expenditure was found to be $10.5 \mathrm{kj} / \mathrm{min}$. which increased up to $11.2 \mathrm{kj} / \mathrm{min}$. during evening hours.
\end{abstract}

\section{INTRODUCTION}

Agriculture is the primary source of employment for women in most of the developing countries. In India 27 crore of women are engaged in agriculture in rural sector. Because of the low literacy rate, a large section of women are compelled to work in field as labourers. There are several studies that reveal that an active women participate in several activities for the cultivation of wheat but there is hardly any literature that reveals the physiological workload and biomechanical stress of women while performing wheat harvesting activity. During the activity they adapt unnatural body posture due to which their physiological workload increase and also they faces many types of musco-skeletal problems as a result the efficiency of women to work decreases to a greater extent.

Hence in view of the above, an attempt has been made to study the physical fitness, time and activity profile and physiological stress of women harvesting wheat.

\section{METHODOLOGY}

The study was carried out on 20-farm women involved in wheat harvesting activity each falling between the two age group viz., 25-35 and 3545 years. The field experiment was conducted

*Address all correspondence to: K.Singh. in the month of April-May for wheat harvesting and bundling activity. During the experiment, various parameter viz., time and activity profile, physiological and biomechanical stress were studied as follows:

Time and Activity Profile: Stopwatch was used for recording time and pedometer was used for measuring the distance traveled.

\section{Assessment of Physiological Stress}

1. Heart Rate: Heart rate was recorded using Polar Vantage NV Heart Rate Monitor. In the morning resting heart rate/min. of the respondents for 5 min was recorded and after that she started her activity and her working heart rate/ min and Rating of Perceived Exertion (RPE) were recorded for $20 \mathrm{~min}$. After that she was asked to rest and her recovery heart rate/min. and RPE were recorded till complete recovery or up to maximum of 10 minutes. At the end of the day the working heart rate of respondent was recorded for 20 minutes besides RPE. After that respondents were rest and her recovery heart rate/ min. and RPE was recorded till complete recovery or upto maximum of 10 minutes.

2. Energy Expenditure and TCCW: From the average values of heart rate, energy expenditure, total cardiac cost of work (TCCW) and physiological cost of work for wheat harvesting were calculated with the help of formulae given by Varghese et al. (1995) as 
below:

Energy expenditure $(\mathrm{kj} / \mathrm{min})=0.159^{\prime} \mathrm{AHR}-8.72$

$\mathrm{TCCW}=$ Cardiac cost of work $(\mathrm{CCW})+$ cardiac cost of recovery $(\mathrm{CCW})$ where :

$\mathrm{CCW}=$ Average hear rate $(\mathrm{AHR})+$ Duration of activity

AHR $=$ Average working heart rate - Average resting heart rate

$\mathrm{CCR}=$ Average recovery heart rate - Average resting heart rate 'duration of

activity

TCCW Physiological cost of work = Total time of activity

3. Rating of Perceived Exertion (RPE): RPE-scale developed by Varghese et al. (1994) was used to study the exertion perceived by the subject during and after the activity. It was measured at 5-point continuum for very light, light, moderately heavy, heavy and very heavy exertion respectively.

\section{RESULTS AND DISCUSSION}

1. Physical Characteristics: Mean age of the respondents engaged in wheat harvesting operation was 32 years measuring body height of $158.6 \mathrm{~cm}$ and body weight as $47.7 \mathrm{~kg}$ (Table 1). Fat percentage of women was $43.9 \%$. Aerobic capacity ( $\mathrm{Vo}_{2} \max$ ) was found to be $1.71 / \mathrm{min}$. More than half of the women (70\%) were having ectomorph body type followed by mesomorphs $(20 \%)$ and endomorphs (10\%). On physical fitness index, majority of the respondents were having high average PFI (60\%) followed by good (20\%) below average (15\%) and Good PFI (5\%).

2. Time and Activity Profile: Table 2 depicts that on an average women spent at least 8 hours in wheat harvesting activity and 2 hours in bundling activity per day during which they tie an average of 50 bundles. On an average, women from both the age groups travel $2.2 \mathrm{~km}$ per day while doing wheat harvesting activity and 1.6 $\mathrm{km}$ per day while performing bundling activity.

Table 1: Physical characteristics of selected respondents

\begin{tabular}{|c|c|c|c|c|c|}
\hline \multirow[t]{2}{*}{ Variable } & \multicolumn{2}{|c|}{$\begin{array}{c}25-35 \text { years } \\
(n=10)\end{array}$} & \multicolumn{2}{|c|}{$\begin{array}{c}25-35 \text { years } \\
(n=10)\end{array}$} & \multirow[t]{2}{*}{ Total } \\
\hline & \multicolumn{2}{|c|}{ Mean $\pm S D$} & \multicolumn{2}{|c|}{ Mean $\pm S D$} & \\
\hline Age (years) & 27.7 & 2.4 & 40.2 & 3.0 & 32.0 \\
\hline Height $(\mathrm{cm})$ & 158.8 & 2.0 & 159.2 & 3.9 & 158.6 \\
\hline Weight (kg) & 48.2 & 8.6 & 47.4 & 7.0 & 47.7 \\
\hline Lean body mass (kg) & 25.5 & 2.4 & 25.1 & 2.1 & 25.3 \\
\hline Fat $(\%)$ & 41.0 & 6.0 & 46.8 & 7.0 & 43.9 \\
\hline Body miss index $\left(\mathrm{kg} / \mathrm{m}^{2}\right)$ & 2) 19.4 & 4.2 & 18.9 & 3.3 & 19.1 \\
\hline $\mathrm{Vo}_{2} \max (1 / \mathrm{min})$ & 1.9 & 0.19 & 1.5 & 0.13 & 1.9 \\
\hline
\end{tabular}

On an average a women spent 20 days in wheat harvesting and bundling activity per year. In one year they spent an average of 25 man days in wheat harvesting and 5 man days in bundling activity during which they tie an average of 1000 bundles and travel an approximate distance of $44 \mathrm{~km}$ during wheat harvesting and 32 during bundling activity.

Table 2: Time and activity profile of selected respondent for wheat harvesting andbundling activity for one day

\begin{tabular}{|c|c|c|c|}
\hline Activity & $\begin{array}{l}\text { Activity } \\
25-35\end{array}$ & $\underset{35-45}{\text { Age group }}$ & Total \\
\hline \multicolumn{4}{|l|}{ Wheat Harvesting Activity } \\
\hline $\begin{array}{l}\text { Type of implement } \\
\text { used for performing } \\
\text { the activity }\end{array}$ & $\begin{array}{l}\text { Tradi- } \\
\text { tional } \\
\text { sickle }\end{array}$ & $\begin{array}{l}\text { Tradi- } \\
\text { tional } \\
\text { sickle }\end{array}$ & $\begin{array}{l}\text { Tradi- } \\
\text { tional } \\
\text { sickle }\end{array}$ \\
\hline $\begin{array}{l}\text { Average time spent for } \\
\text { whole day (hrs.) }\end{array}$ & 8 & 8 & 8 \\
\hline $\begin{array}{l}\text { Average distance traveled on } \\
\text { whole day }(\mathrm{km})\end{array}$ & 2.3 & 2.1 & 2.2 \\
\hline \multicolumn{4}{|l|}{ Bundling Activity } \\
\hline $\begin{array}{l}\text { Average distance traveled on } \\
\text { whole day }(\mathrm{km})\end{array}$ & 1.5 & 1.7 & 1.6 \\
\hline $\begin{array}{l}\text { Average time spent for } \\
\text { bundling activity/day (hrs). }\end{array}$ & 2 & 2 & 2 \\
\hline $\begin{array}{l}\text { Average number of } \\
\text { bundles tied per day }\end{array}$ & 50 & 50 & 50 \\
\hline
\end{tabular}

3. Physiological Stress: Physiological stress of the wheat harvesters was determined on the basis of various parameters like average and peak heart rate, energy expenditure, physiological cost of work and rating of perceived exertion (RPE) while performing the activity.

Table 4 shows that both average and peak heart rate was more for older age group as compared to younger group for both morning and evening. Also slight increase in average and peak heart rate was reported during evening in both younger and older group. Similar kind of trend was also observed for energy expenditure. For bundling activity, same kind of trend was observed i.e. both average and peak heart rate was found to be more in older group than in younger group. The classification of workload on basis of average and peak heart rate and energy indicated that the activity of wheat harvesting was graded between moderately heavy and heavy while bundling activity was graded between heavy and very heavy.

\section{CONCLUSION}

Summarisingly women performing wheat 
Table 4: Classification of workload based on average and peak heart rate

\begin{tabular}{|c|c|c|c|c|c|c|c|c|c|c|c|c|}
\hline \multirow[t]{3}{*}{ Activity } & \multicolumn{4}{|c|}{ Working heart rate beats/min } & \multicolumn{4}{|c|}{ Energy expenditure $\mathrm{kj} / \mathrm{min}$} & \multicolumn{4}{|c|}{ Classification of workload } \\
\hline & \multicolumn{2}{|c|}{ Average } & \multicolumn{2}{|c|}{ Peak } & \multicolumn{2}{|c|}{ Average } & \multicolumn{2}{|c|}{ Peak } & \multicolumn{2}{|c|}{ Average } & \multicolumn{2}{|c|}{ Peak } \\
\hline & $I$ & II & $I$ & II & $I$ & II & $I$ & $I I$ & $I$ & II & $I$ & II \\
\hline \multicolumn{13}{|c|}{ Wheat Harvesting Activity } \\
\hline Morning & 115.9 & 127.1 & 130.0 & 139.9 & 9.7 & 11.4 & 11.9 & 12.9 & MH & $\mathrm{H}$ & $\mathrm{H}$ & $\mathrm{VH}$ \\
\hline Evening & 120.8 & 132.7 & 139.7 & 14.4 & 10.4 & 12.0 & 12.7 & 13.6 & $\mathrm{H}$ & $\mathrm{H}$ & VH & $\mathrm{VH}$ \\
\hline \multicolumn{13}{|l|}{ Bundling Activity } \\
\hline Evening & 132.0 & 136.2 & 142.3 & 144.9 & 12.2 & 12.9 & 13.9 & 14.3 & $\mathrm{H}$ & VH & VH & $\mathrm{VH}$ \\
\hline
\end{tabular}

harvesting activity, harvest the wheat during morning hours and bundling the harvested wheat during evening hours. All of the respondents used traditional sickle for cutting the wheat. During wheat harvesting activity from morning till evening women usually adapts squatting posture and they continue to work in this posture for long duration without adapting any other posture due to which they reported severe pain in lower back and knees. Hence periodic training programmes should be organized to emphasize on educating workers regarding recognition of musculo-skeletal disorders and importance of rest pauses and maintaining proper posture while performing agricultural activities.

\section{REFERENCES}

Chauhan, M.K.: An Ergonomic Study on Job Fitness Compatibility in Women Employed in Different Occupations. Ph.D. Thesis, SNDT Women's University, Mumbai (1977).

Chauhan, M.K. and Saha, D.N.: Acceptable limits of physiological workload for physically active Indian women. Advance Training Course in Ergonomics, SNDT Women's University, Mumbai (1999).

Varghese, M.A., Saha, P.N. and Atreya, N.: A rapid appraisal of occupational workload from a modified scale of perceived exertion. Ergonomics, 37(3): 485-491 (1994).

Varghese, M.A., Atreya, N. and Saha, P.N. 1995. An ergonomic evaluation of work in selected meal preparation at two different heights of kitchen platform. Ergonomic Studies in India, SNDT Women's Universtiy, Mumbai (1995). 